\title{
RELIABILITY OF MECHANICAL SYSTEM OF SYSTEMS
}

\author{
El Hami Abdelkhalakl and ITMI Mhamed \\ LMN-INSA Rouen Normandie, Normandy University, \\ ST Etienne du Rouvray FRANCE
}

\begin{abstract}
In this paper, we present a new methodology about reliability of systems of systems. We present also an example which combines the information transformation in complex systems and virtual design of this system based on finite element analysis. This example is help to balance the performances and the costs in complex system, or provide the optimal solution in manufacturing design. It can also update the existing design of component by changing the new design of this component.
\end{abstract}

\section{KEYWORDS}

Reliability, Systems of systems, Simulation

\section{INTRODUCTION}

The manufacturing industrials of car or aircraft are the term that covers a wide range of companies and organizations involved in the design, development, manufacture, marketing, and selling. To minimize the manufacturing costs of the relative products, some virtual methods are developed to numerically investigate the product manufacturing process through all the fields mentioned above. This report tries to describe the information transformations between different subsystems in the complex manufacturing system and introduces the finite element simulation in the numerical predictions of some mechanical structures or processes. Meanwhile, the differences between system of systems and the complex mechanical system are briefly discussed.

\section{COMPLEX MECHANICAL SySTEMS IN AIRCRAFT MANUFACTURING INDUSTRIALS}

The aerospace manufacturer is a high technology industry which is a company or individual involved in the various aspects of designing, building, testing, selling, and maintaining aircraft, aircraft parts, missiles, rockets or spacecraft. Aircraft manufacturing is one of aerospace manufacturing and it is important in civil, industry, military and scientific research. This report focuses on introducing the design of global aircraft mechanic system according to various sub mechanical systems. The finite element simulation is proposed to numerically study the properties of each sub mechanical systems and virtually research the global properties of aircraft 
system (client requirements: cost and strength for example); A platform of system is needed to transfer the information from requirements to the end manufacturing.

Aircraft manufacturing system is a complex system which includes various sub systems. The performance of this global system is closely related to each subsystem. For instance, the mechanical properties of airplane are depended on the mechanical properties of each subsystem. Figure 1 shows us the strength design of global airplane and its components. In this report, we try to integrate the strength design of subsystems or components which predicted by the finite element simulations into the global strength in order to fulfill the different needs of customers. All of the resources like manufacturing machines, metal forming processes, materials, and customer requirements should be integrated together in this virtual tool.

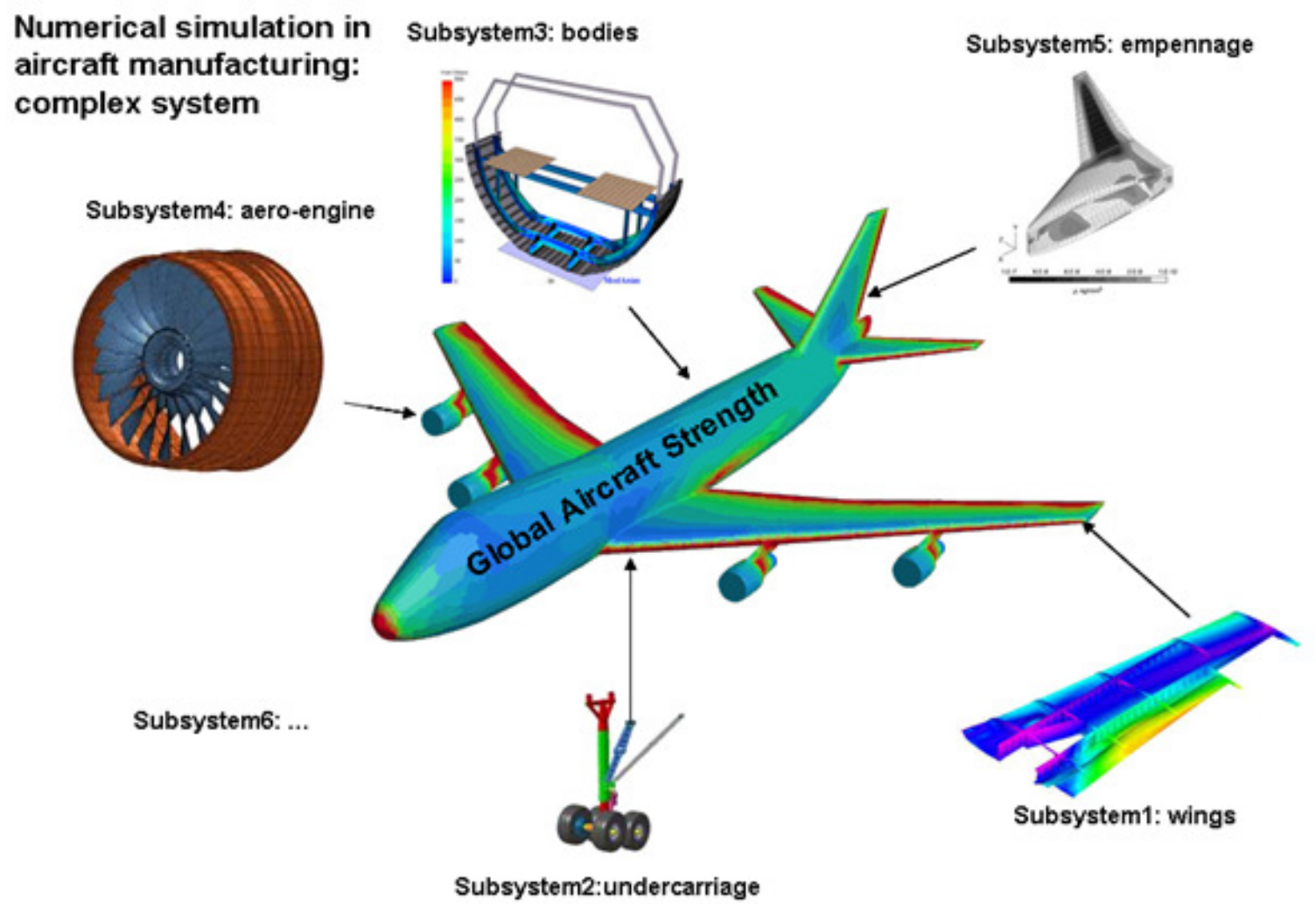

Figure 1. Global aircraft strength and the strengths in different parts.

In the global strength design of aircraft, the strength, the weight and the costs are three important aspects must be taken into account. Generally speaking, the cost should be controlled in a certain range, while the total weight is as light as possible and the strength must fulfill the demand of customers during the aircraft design process. This will demand firstly to transfer the global information into each subsystems or components and then focus on the component productions, like undercarriage, wings, aero-engines and empennage. Each component will have its own demand on strength, weight and costs. This is the aspect of the assignment of customer requirements from global strength design to component strength design. The other aspect is to numerically predict the strength of component with different design schemes and chose the optimal one based on the finite element simulation and other optimization algorithms. For 
example in wing design (see Figure 2), the optimal design scheme can be obtained with the help of finite element simulation. Some performances like, loading capacity, fatigue performance and aerodynamic structure can be numerically optimized for industrials.

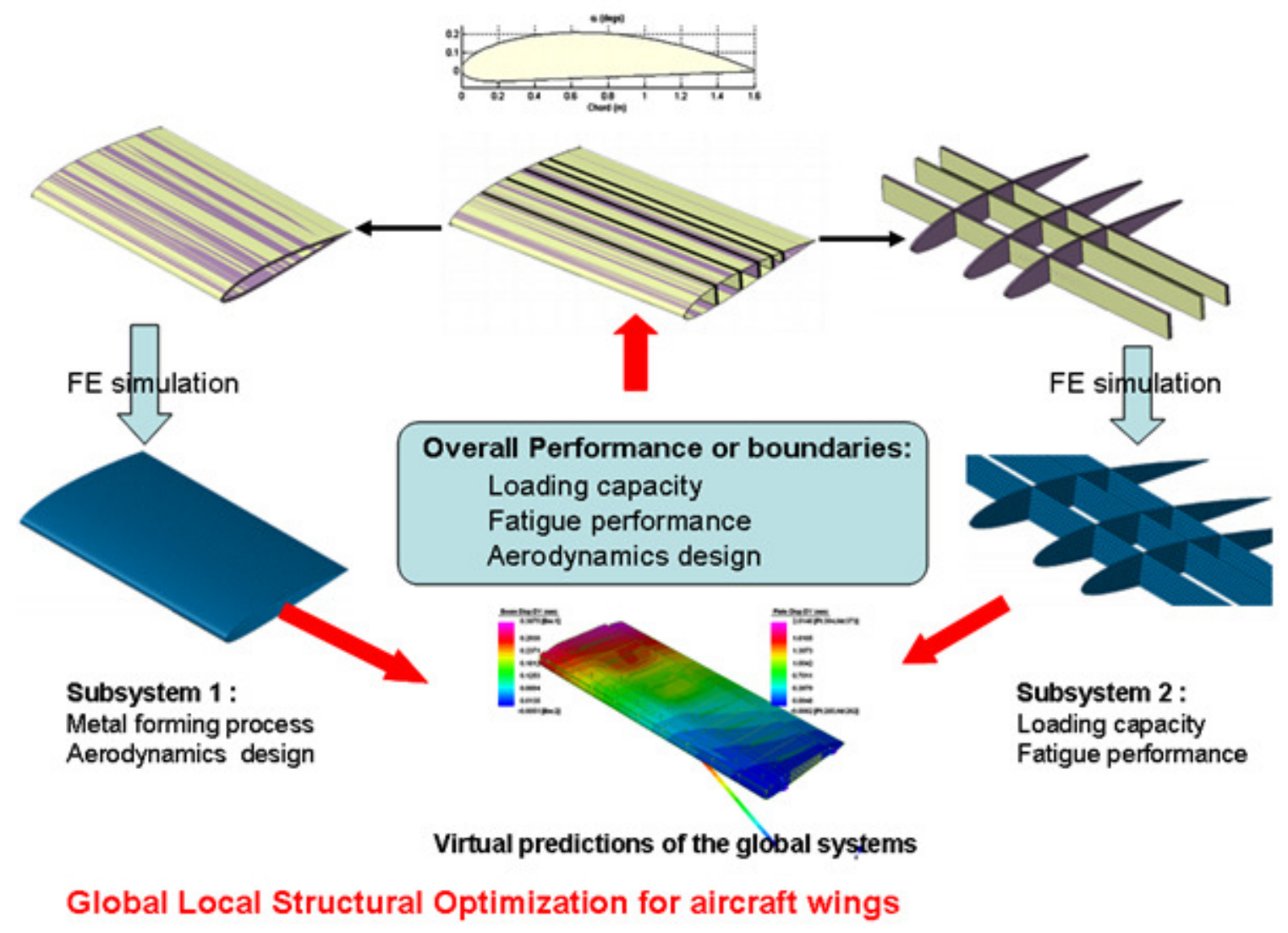

Figure 2. Wing's design and its strength simulation with the help of finite element simulation.

Structure design:

1. Aerodynamic design;

2. Structure strength;

Materials:

1. Strength-to-weight ratio ;

2. Cost: metals, composite material, new function material...;

3. Elastoplastic-damage response in complex conditions: temperature, fatigue...; 
Metal forming process

1. Metal forming and piece strength;

2. Machining cost

3. Machining or forming time: design cycle...;

Rivet connection:

1. Connection strength: loading, fatigue...;

2. Stress concentration;

3. And so on....

\section{SIMUlATIONS}

The aspects listed above (structure design, material chosen, forming processes, rivet connection...) can be studied in the finite element simulation and their mechanical properties can be numerically predicted. Some numerical simulations of components which can be used as the indicators are shown in Figure 3 (rivet connection), Figure 4 (strength of thread) and Figure 5 (pipe bending process).

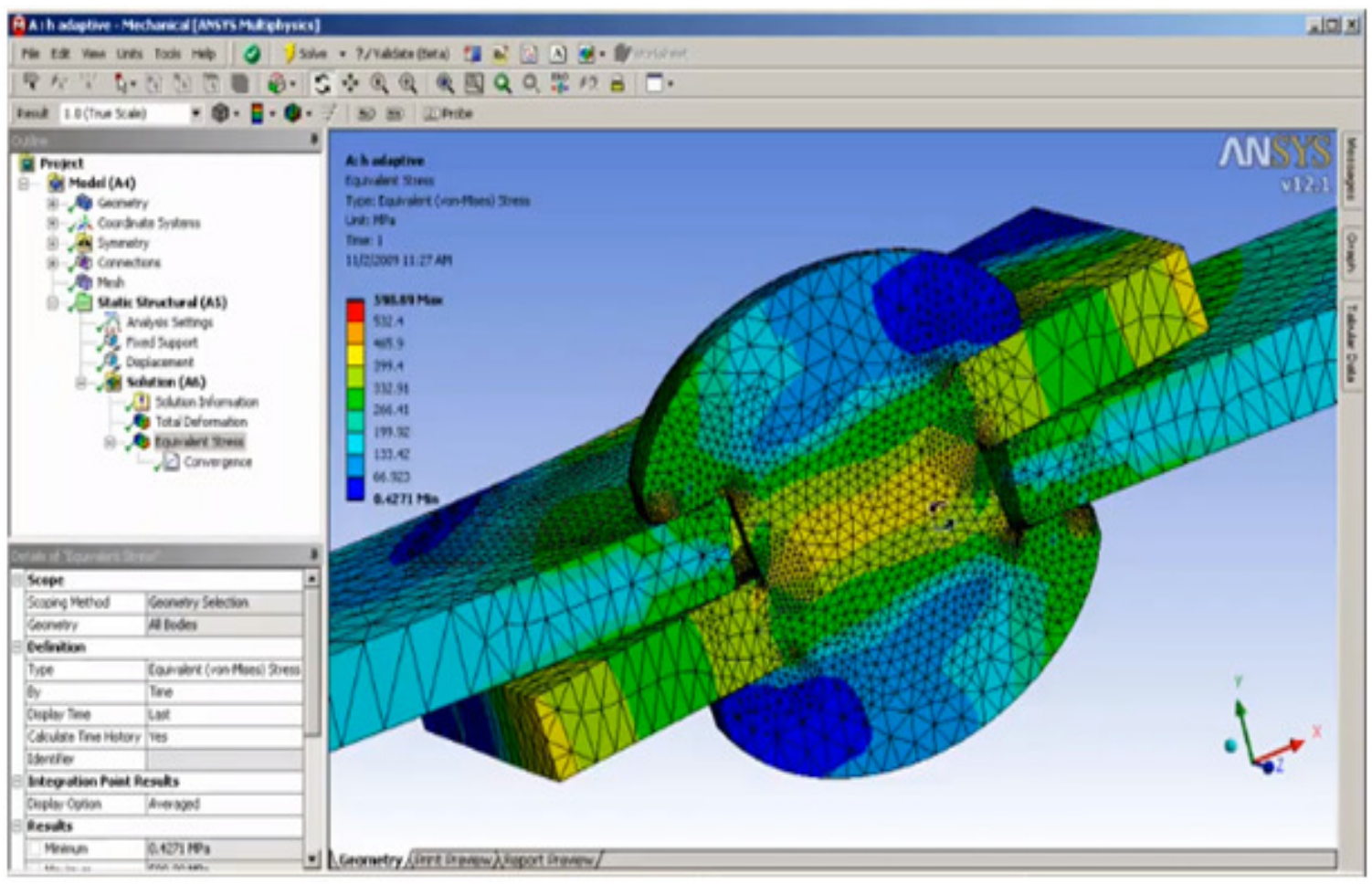

Figure 3. The prediction of linking strength through Finite Element Simulation 


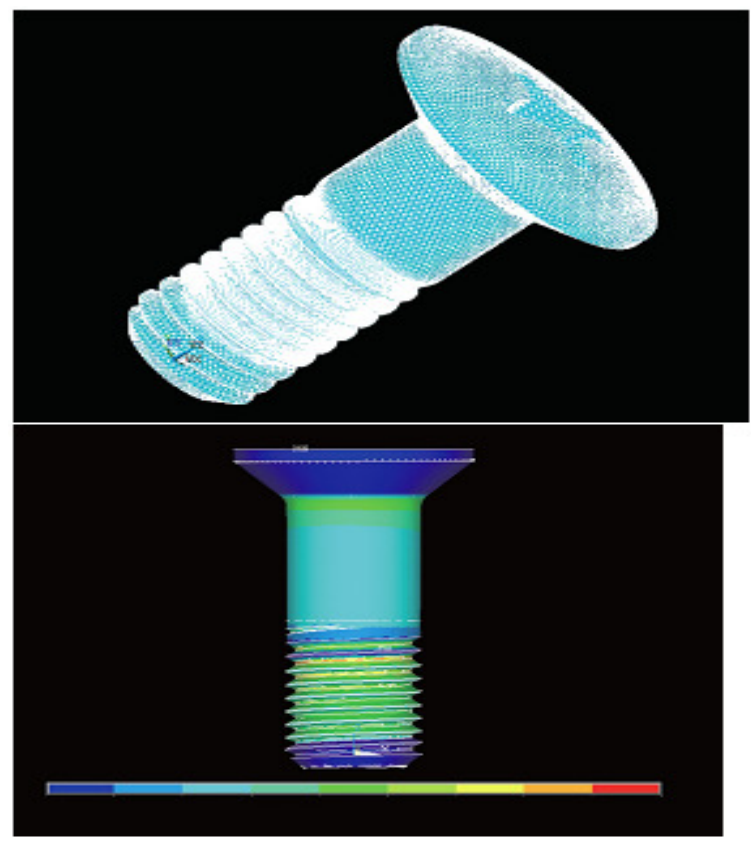

Figure 4. The prediction of stress concentration in thread through Finite Element Simulation

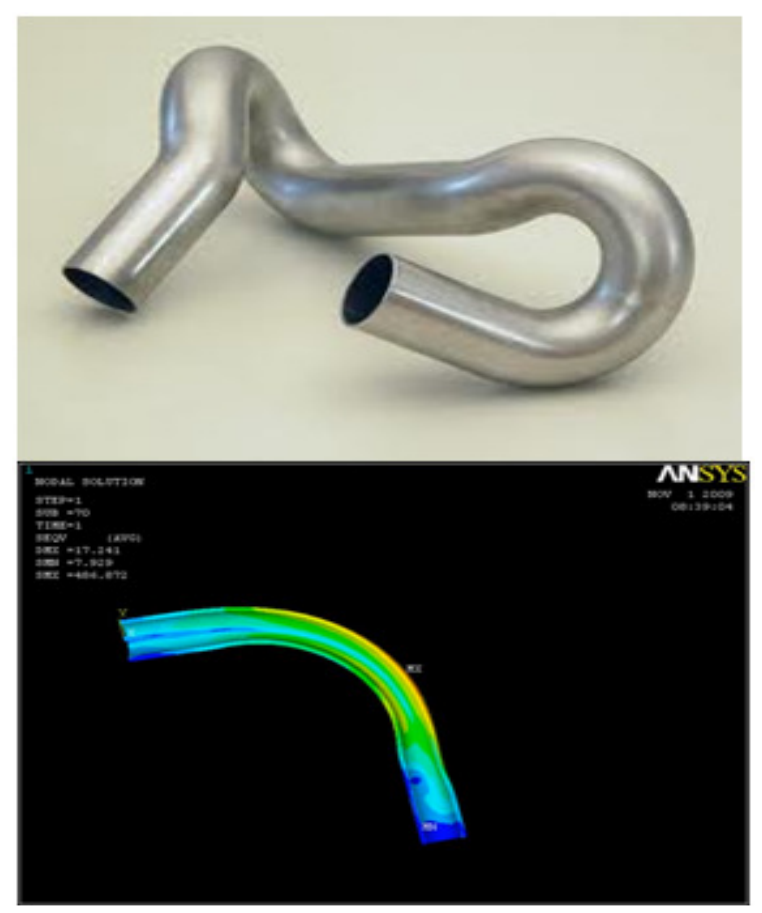

Figure 5. The prediction of pip bending process for aero-engine through Finite Element Simulation

Based on the numerical results about the components of aircraft, the global strength, weight and cost will be obtained when these components are assembled together, as shown in Figure 6. 


\section{Global Aircraft Strength Design}

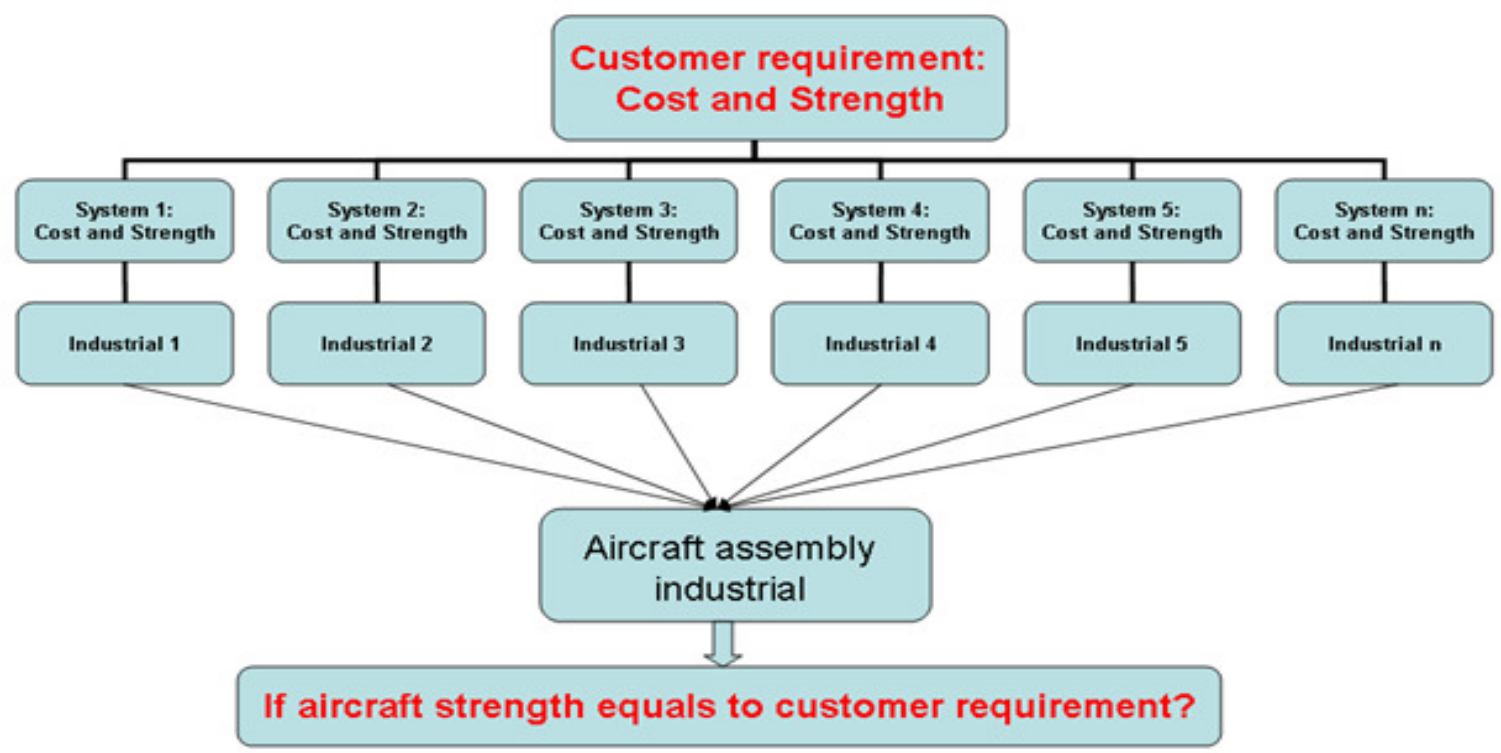

Figure 6. Assembly of the subsystems

The numerical predictions based on finite element simulation for each component can virtually study the manufacturing and designing processes of components. A platform of system is also needed to transfer requirements (cost, weight and strength) to from global design to the end manufacturing, as follows:

Decomposition of aircraft virtual design: Platform to transfer requirements
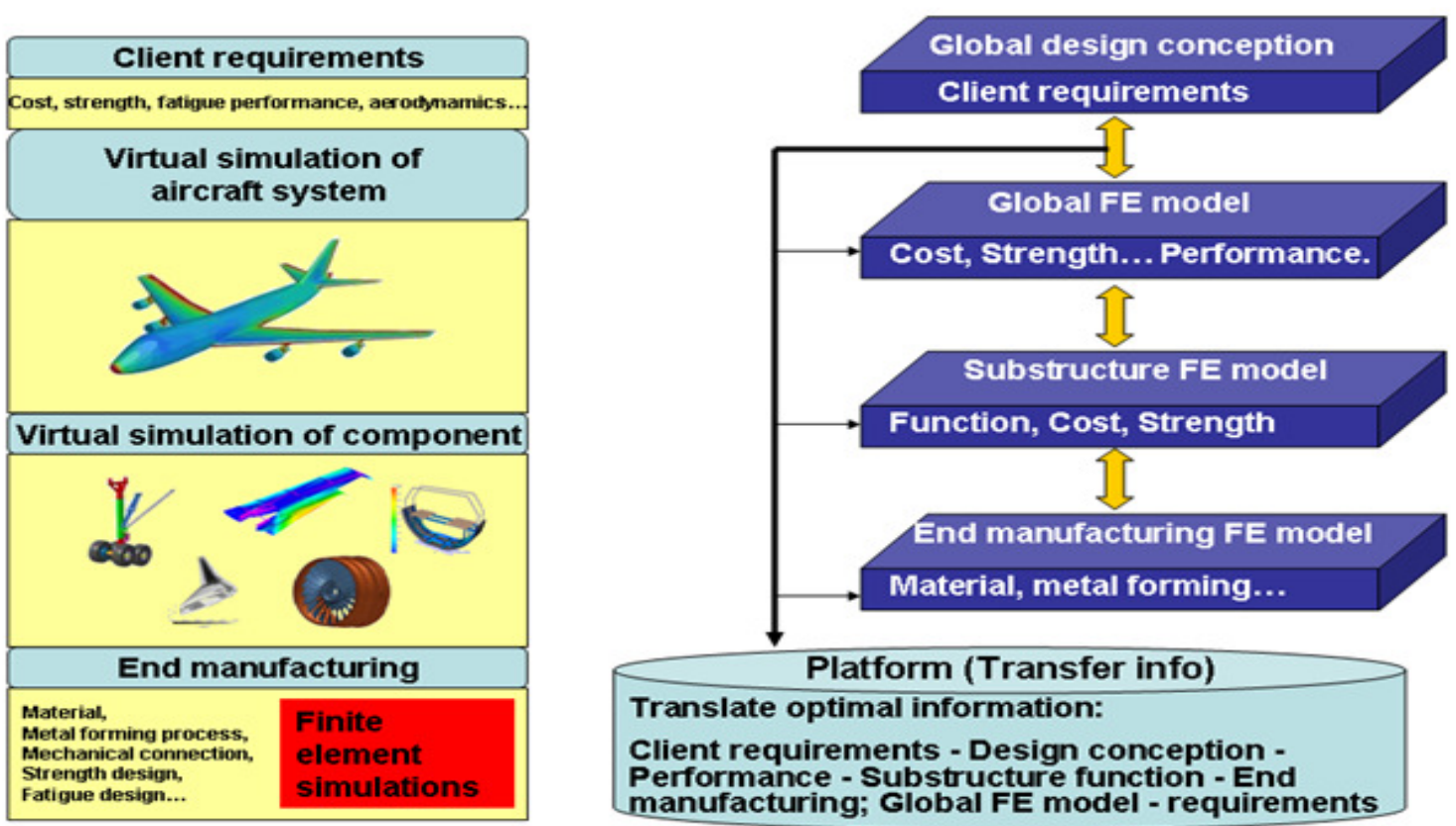

Figure 7. Information transformation between global requirements and the requirements in subsystems 
In this report, we try to present an example which combines the information transformation in complex systems and virtual design of this system based on finite element analysis. This example is help to balance the performances and the costs in complex system, or provide the optimal solution in manufacturing design. It can also update the existing design of component by changing the new design of this component.

\section{Numerical Platforms BaSed On Finite Element Simulation}

\subsection{Numerical Platform}

Based on the above description, a numerical platform based on finite element simulation must be build in order to numerically study the mechanical systems. It will be used firstly to simulate metal forming processes and consider the user defined material subroutine which implements advanced material constitutive equations. Secondly, it can be used to simulate the responses (strength, efficiency, fatigue, properties...) of the mechanical structures or connections.... The implementation of this platform is based on ANSYS platform and is described in the following flowchart.

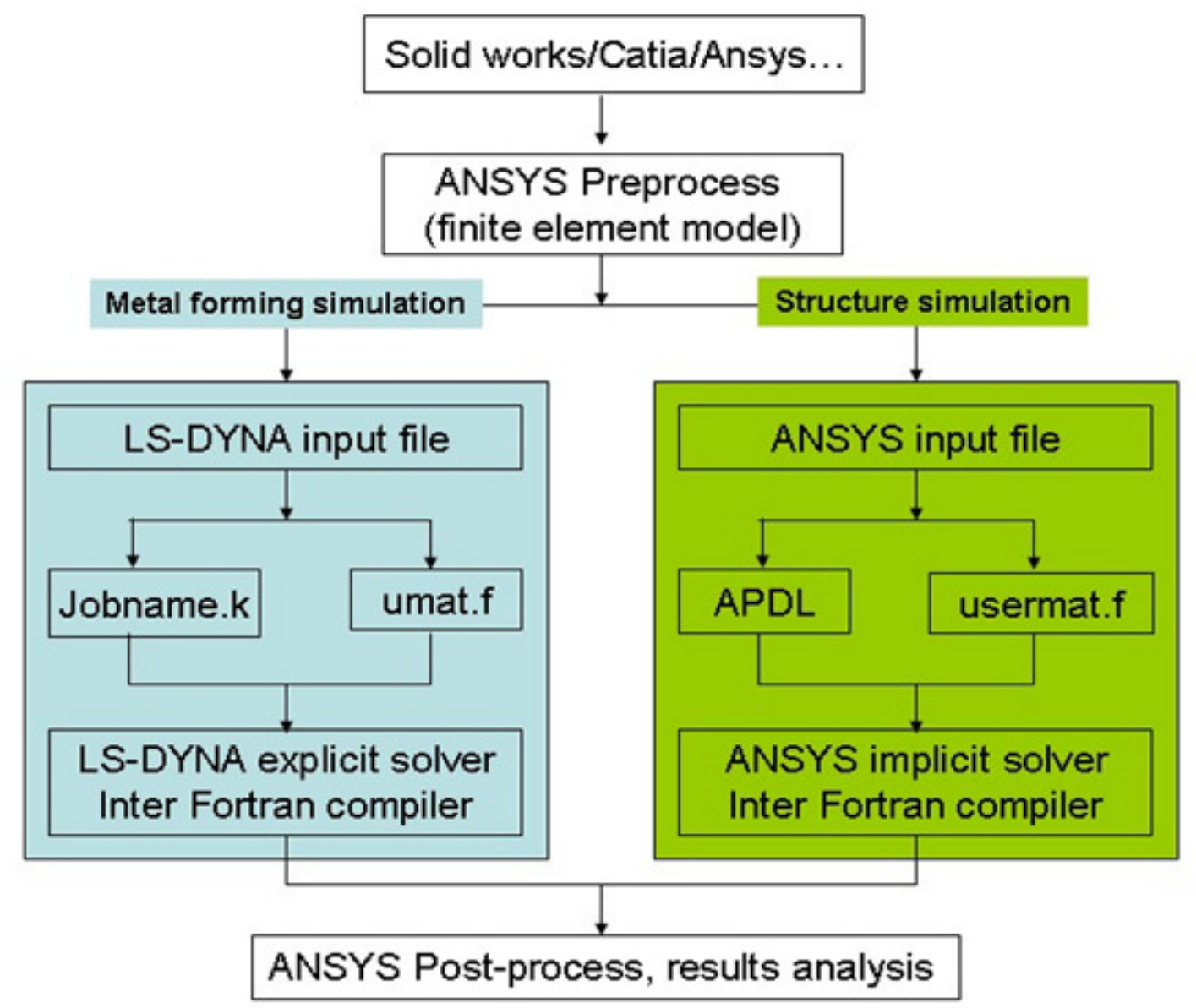

Figure 8. Finite element simulation platform based on Ansys 


\section{CONCLUSIONS}

System of systems in the information field is a collection of task-oriented or dedicated systems that pool their resources and capabilities together to create a new, more complex system which offers more functionality and performance than simply the sum of the constituent systems. Comparing to system of systems, the complex mechanical system is a product (car, airplane and so on) which is composed of some components. Unlike the system of systems, the complex mechanical system cannot leave any components, in other words, each component has its function and their functions are different. The virtual simulation of each component based on finite element method is surly useful in the design and manufacture of complex mechanical system, but it is difficult to used in system of systems according to its conception.

Actually, the numerical simulation is a suitable tool to do the reliability analysis for the mechanical systems. From this point of view, the numerical predictions can be used in system of systems as an indicator of the reliability of subsystems. The finite element analysis can be used to estimate the abilities (strength, fatigue, damage) of each subsystem. For example in the ballistic missile defense system, finite element simulation can be used to predict the mechanical reliability of each defense weapon, or to estimate the usability of this subsystem in the mechanical aspect. However, in the system of systems, all of the subsystems are assumed to be usable and the research key point is its functions. Hence, the bridge between the field of system of systems and the filed of mechanical systems is the requirement of the reliability analysis of mechanical system in the system (of systems).

\section{ACKNOWLEDGEMENTS}

This research is supported by the European Union (EU) with the European Regional Development Fund (ERDF) and Normandy Region.

\section{REFERENCES}

[1] Y. Bao, T. Wierzbicki, On fracture locus in the equivalent strain and stress triaxiality space, International Journal of Mechanical Sciences, 46 (2004) 81-98.

[2] Y. Bao, T. Wierzbicki, On the cut-off value of negative triaxiality for fracture, Engineering Fracture Mechanics, 72 (2005) 1049-1069.

[3] T. Wierzbicki, Y. Bao, Y.-W. Lee, Y. Bai, Calibration and evaluation of seven fracture models, International Journal of Mechanical Sciences, 47 (2005) 719-743.

[4] Y. Bai, Effect of Loading History on Necking and Fracture, in, Massachusetts Institute of Technology, 2008.

[5] Y. Bai, T. Wierzbicki, A new model of metal plasticity and fracture with pressure and Lode dependence, International Journal of Plasticity, 24 (2008) 1071-1096.

[6] D.C.a.P. Drucker, W., Soil mechanics and plastic analysis for limit design., Quarterly of Applied Mathematics, 10 (1952) 157-165. 
[7] F.A. McClintock, A Criterion for Ductile Fracture by the Growth of Holes, Journal of Applied Mechanics, 35 (1968) 363-371.

[8] J.R. Rice, D.M. Tracey, On the ductile enlargement of voids in triaxial stress fields, Journal of the Mechanics and Physics of Solids, 17 (1969) 201-217.

[9] A.L. Gurson, Continuum Theory of Ductile Rupture by Void Nucleation and Growth: Part I---Yield Criteria and Flow Rules for Porous Ductile Media, Journal of Engineering Materials and Technology, 99 (1977) 2-15.

[10] J.L. Chaboche, Anisotropic creep damage in the framework of continuum damage mechanics, Nuclear Engineering and Design, 79 (1984) 309-319.

[11] J. Lemaitre, Coupled elasto-plasticity and damage constitutive equations, Computer Methods in Applied Mechanics and Engineering, 51 (1985) 31-49.

[12] J.C. Simo, J.W. Ju, Strain- and stress-based continuum damage models-I. Formulation, International Journal of Solids and Structures, 23 (1987) 821-840.

[13] K. Saanouni, On the numerical prediction of the ductile fracture in metal forming, Engineering Fracture Mechanics, 75 (2008) 3545-3559.

[14] J. Lemaitre, A course on Damage Mechanics, Springer-Verlag, New York, 1996.

[15] W.A. Spitzig, O. Richmond, The effect of pressure on the flow stress of metals, Acta Metallurgica, 32 (1984) 457-463.

[16] J.C. Simo, R.L. Taylor, Consistent tangent operators for rate-independent elastoplasticity, Computer Methods in Applied Mechanics and Engineering, 48 (1985) 101-118.

[17] J.C. Simo, R.L. Taylor, K.S. Pister, Variational and projection methods for the volume constraint in finite deformation elasto-plasticity, Computer Methods in Applied Mechanics and Engineering, 51 (1985) 177-208.

[18] J.L. Chaboche, G. Cailletaud, Integration methods for complex plastic constitutive equations, Computer Methods in Applied Mechanics and Engineering, 133 (1996) 125-155

\section{AUTHORS}

Abdelkhalak El Hami is a Full Professor at INSA Rouen, Normandy France, as well as Deputy Director of LMN and director of mechanical engineers. He's research activities include reliability-optimization systems. He has supervised 38 $\mathrm{PhD}$ theses. He also is the author and co-author of more than a twenty books and more than 550 papers published in international journals and conferences. He has a doctorate in engineering sciences from the University of Franche-Comté in France (1992). He received his Habilitation diploma to supervise research (HDR) in 2000. He's Editor in chef of 3 Set of international Book, ISTE, Wiley and Elsivier.

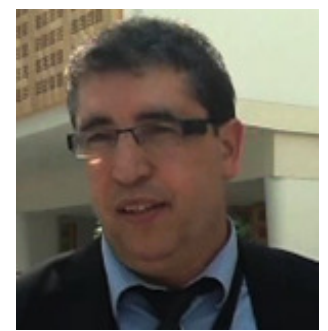


Mhamed Itmi earned his PhD in Probability Theory and Statistics in 1980 and second PhD in Computer Science in 1989. He received his Habilitation Diploma to supervise research (HDR) in 2006 with the focus on the modelling and simulation of distributed discrete event systems. He managed different logistics and transportation research projects and supervised several $\mathrm{PhD}$ theses. He also is the author and coauthor of more than 100 papers published in international journals, conferences and books. His research presently focuses on autonomous systems. He is an Associate Professor at the INSARouen, France.

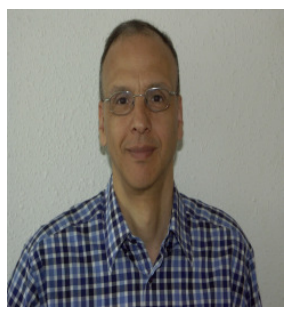

